\title{
Padronização de ensaio imunoenzimático para pesquisa de anticorpos das classes IgM e IgG anti-Toxoplasma gondii e comparação com a técnica de imunofluorescência indireta
}

\author{
Standardization of enzyme-linked immunosorbent assay ELISA to detect \\ anti-Toxoplasma gondii IgM and IgG antibodies, and comparison with \\ the indirect immunofluorescence technique
}

\author{
Cláudia Maria Antunes Uchôa', Rosemere Duarte' ${ }^{2}$, Valmir Laurentino-Silva ${ }^{2}$, Giani Maria \\ Coutinho Alexandre ${ }^{3}$, Humberto Gomes Ferreira ${ }^{3}$ e Maria Regina Reis Amendoeira ${ }^{3}$
}

\begin{abstract}
Resumo A sorologia tem sido o método de escolha para o diagnóstico da toxoplasmose. Devido a isto, padronizamos um ensaio imunoenzimático (ELISA) e comparamos seus resultados com a técnica de imunofluorescência indireta (IFI). A técnica padronizada apresentou na pesquisa de IgG sensibilidade (S) de 96,7\% e especificidade (E) de 75\%, com valor de predição de positividade (VPP) de 83,3\% e de negatividade (VPN) de 94,7\%, com uma concordância ajustada (K) de 73,5\%. A IFI apresentou S de 83,8\%, E de 79,1\% com VPP de 83,8\% e VPN de 79,1\% com K de $63 \%$. A concordância bruta entre os dois testes (ELISA/IFI) foi de $88,3 \%$ para pesquisa de IgG e de $81,5 \%$ para pesquisa de IgM, sendo o $\mathrm{K}$ de $70,8 \%$ para $\lg \mathrm{G}$ e de $1,3 \%$ para IgM, sendo o índice de correlação (r) de 0,556 para IgG e de -0,023 para IgM. Podemos concluir que a ELISAIgG padronizada é indicada nos processos de triagem sorológica, sendo a ELISA-IgM desaconselhada uma vez que apresentou baixos índices de concordância ajustada com a técnica de referência, sugerindo pouca confiabilidade dos resultados.
\end{abstract}

Palavras-chaves: ELISA. Imunofluorescência. Toxoplasma gondii. Toxoplasmose. Sorologia. Diagnóstico.

Abstracts Serology has been the most popular method to diagnose toxoplasmosis. Accordingly, this study standardizes an enzyme-linked immunosorbent assay (ELISA) and compares its results with the IFI technique. In the IgG detection test, the standardized technique presented a sensibility (S) of $96.77 \%$, a specificity (SP) of $75 \%$, with a positive predictive value (PPV) of $83.33 \%$, a negative predictive value (NPV) of $94.74 \%$, and an adjusted concordance (K) of $73.50 \%$. The IFI exhibited $83.87 \%$ for S, $79.16 \%$ for SP, $83.81 \%$ for PPV, $79.16 \%$ for NPV, and $63 \%$ for $K$. The rough concordance between these two tests (ELISA/IFI) was $88.35 \%$ for the IgG detection test and $81.55 \%$ for the $\operatorname{lgM}$ detection test. $K$ was $70.82 \%$ and $1.31 \%$ for $\lg G$ and $\lg M$, respectively, the correlation index $(r)$ being 0.556 for $\mathrm{lg} G$ and -0.023 for $\mathrm{lgM}$. We can conclude that standardized ELISA-IgG is indicated in serologic selection processes, whereas the ELISA-IgM is not recommended for presenting low values for the adjusted concordance with the reference technique, which suggests not very reliable results.

Key-words: ELISA. Immunofluorescence test. Toxoplasma gondii. Toxoplasmosis. Serology. Diagnosis.

\footnotetext{
1. Disciplina de Parasitologia. Departamento de Microbiologia e Parasitologia. Instituto Biomédico. Universidade Federal Fluminense/ FIOCRUZ; 2. Departamento de Ciências Biológicas. Escola Nacional de Saúde Pública/FIOCRUZ e 3. Laboratório de Protozoologia. Instituto Oswaldo Cruz/FIOCRUZ

Endereço para correspondência: Dra Claudia MariaAntunes Uchôa. Departamento de Microbiologia e Parasitologia. Instituto Biomédico/ Universidade Federal Fluminense. R. Professor Hernani de Mello 101, São Domingos, 24210-130 Niterói, RJ, Brasil.

Fax: 55216205266

E-mail: uchoa@radnet.com.br

Recebido para publicação em 18/8/98.
} 
A toxoplasmose é uma infecção cosmopolita, cujo agente etiológico é o Toxoplasma gondiiz2 apresentando alta prevalência na população humana. O diagnóstico clínico torna-se difícil por ser um processo sistêmico, com baixa parasitemia e sintomas e sinais clínicos genéricos o que leva a confusão com outras afecções de etiologias diversas, necessitando de técnicas laboratoriais para sua confirmação ${ }^{125}$. O diagnóstico parasitológico não é realizado com facilidade por necessitar de laboratórios e técnicos especializados, apresentar demora na obtenção de resultados (isolamento) ${ }^{13}$, e em alguns casos apresentar metodologias baseadas na biologia molecular de custo elevado ${ }^{25}$.

Atualmente, a metodologia mais utilizada para o diagnóstico da toxoplasmose consiste na pesquisa de anticorpos das classes lgM e lgG, a fim de que se possa estabelecer a fase de infecção, embora já esteja sendo usado a detecção de $\lg \mathrm{A}^{2431}$ como indicador de fase aguda. Diversas técnicas sorológicas tem sido empregadas no diagnóstico da toxoplasmose com grande eficiência e rapidez como podemos citar a técnica de Sabin-Feldman ${ }^{27}$; a imunofluorescência indireta (IFI) ${ }^{9}{ }^{12}$, a hemaglutinação $(\mathrm{HA})^{16}$; a fixação de complemento (FC') ${ }^{9}$, a enzyme linked immunosorbent assay (ELISA) ${ }^{82} \mathrm{e}$ a immunosorbent agglutination assay (ISAGA) ${ }^{315}$.

Vários autores ${ }^{91128}$ têm comparado as técnicas de IFI, ELISA e FC' verificando boa concordância entre os resultados e sugerem que a técnica de ELISA, em futuro próximo, poderá substituir a técnica de IFI. Por outro lado, Van Knapen ${ }^{33}$ relata que muitas vezes observam-se que a concordância entre os resultados obtidos por IFI e ELISA não é absoluta e sugere que estas diferenças sejam devidas ao uso de antígenos distintos - íntegro na IFI e solúvel na ELISA - detectando, neste último, anticorpos de aparecimento mais tardio além da diferença de qualidade entre os fabricantes de conjugados fluorescentes e enzimáticos ${ }^{33}$.

Neste trabalho propusemo-nos a padronizar uma ELISA avaliando suas qualidades fixas (Sensibilidade, Especificidade, Concordância Ajustada) e variáveis (Valor de Predição de Positividade e Valor de Predição de Negatividade) ${ }^{32}$ e comparar os resultados com a técnica de IFI na pesquisa de anticorpos da classe $\lg G$ e $\lg M$ em quatro grupos de indivíduos (indivíduos considerados normais, pacientes com clínica sugestiva de toxoplasmose, gestantes e pacientes infectados pelo vírus causador da síndrome da imunodeficiência adquirida - HIV com sorologia para toxoplasmose).

\section{MATERIAL E MÉTODOS}

Os soros utilizados foram colhidos de 103 indivíduos do Rio de Janeiro, sendo 28 pacientes do setor de infectologia do Hospital Evandro Chagas (HEC) com clínica sugestiva de toxoplasmose e considerados imunocompetentes por não possuírem histórico de comprometimento do sistema imunitário (grupo A), 30 gestantes do setor de pré-natal do Instituto Fernandes Figueira (IFF) (grupo B), 28 pacientes em diferentes fases de infecção pelo HIV e com sorologia positiva pela IFI para toxoplasmose (grupo C) e 17 indivíduos considerados normais por não apresentarem nenhuma alteração sugestiva de infecção (grupo D, para obtenção de parâmetros para cálculo de cutoffe avaliação das qualidades fixas e variáveis das técnicas sorológicas utilizadas.

Imunofluorescência Indireta (IFI). Utilizou-se a reação de Imunofluorescência Indireta (IFI) ${ }^{9}$, sendo o antígeno produzido no laboratório, utilizando a cepa de T. gondii (amostra cedida pelo Dr. Isnard Teixeira à Escola Nacional de Saúde Pública e mantida no laboratório de Imunidade Celular e Humoral - Instituto Oswaldo Cruz) a partir de lavado peritoneal de camundongos Swiss Webster previamente inoculados, seguida de três lavagens com solução salina tamponada $0.01 \mathrm{M}$ pH 7.2 (PBS) sob centrifugação a $700 \mathrm{~g} / 10$ minutos e conservados a temperatura de $4^{\circ}$ a $8^{\circ} \mathrm{C}$. A técnica foi realizada com os soros diluídos em solução salina tamponada $0.01 \mathrm{M} \mathrm{pH} 7.2$ (PBS), ao quádruplo, a partir de 1:16 até 1:4096. A partir daí, as diluições eram feitas ao dobro. Foi usado soro conjugado fluorescente anti-humano na diluição de 1:50 tanto para os conjugados antiIgM quanto anti-IgG humano (conjugado anticadeia pesada com isotiocianato de fluoresceína - SIGMA).

Todos os soros IgM positivos foram passados em coluna de Sephacrill S-100HR (PharmaciaBiotech) e submetidos a pesquisa de fator reumatóide com o kit de diagnóstico Biolatex RF (Biocientífica SA).

Enzyme Linked Immunosorbent Assay ELISA. Preparo do antígeno: o antígeno foi obtido do exsudato peritoneal de camundongos infectados com a mesma cepa de T. gondii 
utilizada para IFI. O exsudato foi centrifugado a 40g/10 minutos, para separação das células do hospedeiro. Este sobrenadante foi centrifugado a $700 \mathrm{~g} / 10$ minutos e o sedimento rico em parasitas suspenso em PBS estéril e centrifugado a $700 \mathrm{~g} / 10$ minutos, repetindo-se a operação mais uma vez para lavar o antígeno. Após esta última centrifugação o sedimento foi suspenso em uma pequena quantidade de PBS estéril (cerca de $0,5 \mathrm{ml}$ ), e procedeu-se a quebra dos parasitas pela técnica de congelamento rápido com metanol e gelo seco e descongelamento em banho-maria a $56^{\circ} \mathrm{C}$, até não se obter parasitas íntegros através da visualização de parte do material em microscopia óptica. A seguir o material foi centrifugado à $12000 \mathrm{~g} / 5$ minutos para separação do antígeno solúvel. Fez-se então dosagem da proteína ${ }^{19}$ e padronização da concentração ideal de proteínas, através de soros padrões reagente e não reagente, sendo o material aliquotado e congelado a $-20^{\circ} \mathrm{C}$ para posterior diluição em tampão carbonato bicarbonato $\mathrm{pH} 9,0$, na sensibilização das placas ${ }^{33}$.

Procedimento técnico: utilizou-se placas de poliestireno com 96 poços de fundo plano (Corning-Sigma), sensibilizadas com $100 \mathrm{ml}$ de antígeno a $1,25 \mu \mathrm{g} / \mathrm{ml}$ por poço, diluído em tampão carbonato bicarbonato pH 9,0. Após incubação a $4^{\circ} \mathrm{C}$ overnight a placa foi lavada duas vezes com PBS Tween $0,05 \%$ (PBS-T) e adicionou-se o soro diluído ao quádruplo, a partir de 1:16 até 1:4096, em solução de leite desnatado (Molico) 1\% em PBS-T para bloqueio, colocando-se $100 \mu$ l de cada diluição nos respectivos poços. A placa foi então incubada à $37^{\circ} \mathrm{C} / 45$ minutos em câmara úmida, sendo lavada três vezes com PBS-T. Colocou-se o soro conjugado com peroxidase (SIGMA) previamente titulado anti-IgM ou anti-IgG humano, submetendo-se a placa a nova incubação a $37^{\circ} \mathrm{C}$ por $45 \mathrm{~min}$ em câmara úmida. Ao seu término, fez-se 3 lavagens (três) em lavadora automática e acrescentou-se $100 \mathrm{ml}$ de solução reveladora com substrato (tampão fosfato citrato $\mathrm{pH} 3,5$ com $0,01 \mathrm{~g}$ de ortofenilenodiamina (OPD) e peróxido de hidrogênio - Merck 30\%), colocando-se a placa em câmara escura por $15 \mathrm{~min}$. Após este período, fez-se leitura no leitor EIA Microplate Reader da SIGMA Diagnóstico com comprimento de onda de 490-650 nanometros.

Estabelecimento do cutoff: $O$ estabelecimento do cutoff foi realizado a partir da análise de doze soros padrão negativos e quatro positivos em quatro placas distintas, frente a determinada partida de antígeno. Foi obtido um cutoff de cada placa a partir da média das leituras dos soros negativos adicionado de dois desvios-padrão. Com a finalidade de uniformizar os valores de cutoff foi estimado um fator de correção pela divisão da média dos valores de cutoffpela média das leituras dos soros padrão negativos destas placas $^{18}$. No estudo os soros foram diluídos de $1: 16$ até $1: 4096$ para pesquisa de $\lg \mathrm{g}$ e de $1: 16$ até 1:256 para pesquisa de $\operatorname{lgM}$, sendo considerado como cutoff de cada placa a média da leitura da diluição de 1:16 dos soros negativos, multiplicado pelo fator de correção, pois verificouse que as diferenças entre os cutoff por diluição foram irrelevantes.

Análise estatística: Testes para avaliação de Sensibilidade (S), Especificidade (SP), Confiabilidade (C), Valor de Predição de Positividade (VPP), Valor de Predição de Negatividade (VPN) e Valor de Concordância Ajustada (K) foram realizados no tratamento dos resultados obtidos através das técnicas sorológicas ${ }^{14} 192932$.

Para avaliação da Sensibilidade, Especificidade, Confiabilidade, Valor de Predição de Positividade, Valor de Predição de Negatividade e Valor de Concordância Ajustada foram estabelecidos dois grupos, sendo um constituído por 31 amostras de soros reagentes para IgG anti $T$. gondii (28 pacientes com clínica sugestiva para toxoplasmose e três pacientes em que ocorreu o isolamento) e um segundo grupo constituído por 24 amostras de soros considerados não-reagentes de pacientes sem suspeita clínica (17 pacientes do grupo D e 7 pacientes do grupo B com IgG e IgM negativos).

Devido ao pequeno número de soros reagentes para IgM confiáveis não foi possível determinar as qualidades fixas e variáveis da técnica de ELISA IgM e IFI IgM.

Além destas avaliações, das técnicas individualmente, foram realizadas a análise da copositividade, da conegatividade e o grau de concordância bruta e ajustada entre as duas técnicas estudadas ${ }^{18}$.

A fim de que fosse feita a comparação dos resultados obtidos pela técnica de ELISA dos soros analisados nas diversas placas (valores de cutoff diferentes); utilizou-se a fórmula da unidade arbitrária "Y", através da qual os cutoff das diversas placas puderam ser igualados ao valor numérico 5 , sendo considerados positivos 
os soros com valores superiores a este e como negativos os soros com valores numéricos inferiores a $5(Y=[(A B-C) \times F]+5$ onde $A B=$ valor da absorbância da amostra, $C=$ valor do cutoff, $F=$ fator que é calculado $F=95 / 2-C$ ). A partir dos dados obtidos foi analisada a correlação entre os resultados obtidos por títulos, através das técnicas de ELISA e IFI, para pesquisa de anticorpos das classes IgG e $\lg M$ e a correlação entre o título obtido pela técnica de ELISA e a unidade arbitrária (Y) obtida por esta mesma técnica.

Foram utilizados o índice de correlação de Pearson ( $r$ ) e o teste de qui-quadrado $\left(\chi^{2}\right)$ para análise dos resultados obtidos através do MINITAB/WIN (programa para análise estatística) e tomando como base Levin ${ }^{19}$ e Berquó et al ${ }^{4} \mathrm{e}$ Sounis ${ }^{29}$.

\section{RESULTADOS}

A técnica de ELISA IgG, padronizada, apresentou $96,7 \%$ de sensibilidade e especificidade de $75 \%$, com confiabilidade de $87,2 \%$. O VPP do teste foi de $83,3 \%$, enquanto que o VPN foi de $94,7 \%$ sob prevalência estimada em $78,6 \%$. O valor de concordância ajustada foi de $73,5 \%$, sendo considerado regular.

A técnica de IFI-IgG apresentou $S$ de $83,8 \%$ e E de $79,1 \%$ e confiabilidade de $81,8 \%$. O VPP foi de $83,8 \%$ e o VPN de $79,1 \%$. O valor de $\mathrm{K}$ foi de $63 \%$, sendo considerado regular.

No grupo $A$, dos 28 pacientes com clínica sugestiva para toxoplasmose, apenas $4(14,2 \%)$ foram positivos pela técnica de ELISA-IgM, porém com leituras muito próximas ao valor de cutoff da reação. A técnica de IFI-IgM não apresentou resultados positivos. Os soros que apresentaram resultados positivos pela IFI-IgM (6 - 21,4\%) mostraram-se negativos pela técnica de ELISA.

Nas Tabelas 1 e 2, estão representados os soros reatores nos dois testes, sendo a copositividade e a conegatividade da resposta a cada teste em relação ao outro, de forma pareada, também representadas nas Tabelas 1 e 2. A concordância bruta das respostas aos dois

Tabela 1 - Resultados obtidos com os soros de pacientes dos quatro grupos avaliados obtidos pelas técnicas de ELISA e IFI para pesquisa de anticorpos da classe IgG.

\begin{tabular}{lccc}
\hline & \multicolumn{3}{c}{ ELISA } \\
\cline { 2 - 3 } IFI & positivo & negativo & Total \\
\hline Positivo & 70 & 2 & 72 \\
Negativo & 11 & 20 & 31 \\
\hline Total & 81 & 22 & 103 \\
\hline
\end{tabular}

Conegatividade IFI/ELISA = 67,7\%; Copositividade ELISA/IFI = 86,4\%; Copositividade IFI/ELISA = 97,2\%; Conegatividade ELISA/IFI = $95,4 \%$; Concordância Bruta $=88,3 \% ; \mathrm{K}=70,8 \%$.

Tabela 2 - Resultados obtidos com os soros de pacientes dos quatro grupos avaliados obtidos pelas técnicas de ELISA e IFI para pesquisa de anticorpos da classe IgM.

\begin{tabular}{|c|c|c|c|}
\hline \multirow[b]{2}{*}{ IFI } & \multicolumn{2}{|c|}{ ELISA } & \multirow[b]{2}{*}{ Total } \\
\hline & positivo & negativo & \\
\hline Positivo & 1 & 5 & 6 \\
\hline Negativo & 14 & 83 & 97 \\
\hline Total & 15 & 88 & 103 \\
\hline
\end{tabular}

Copositividade ELISA/IFI = 6,6\%; Conegatividade IFI/ELISA = 85,5\%; Copositividade IFI/ELISA = 16,6\%; Concordância Bruta = 81,5\%; Conegatividade ELISA/IFI = 94,3\%; $\mathrm{K}=1,31 \%$.

testes estudados foi de $88,3 \%$ para a pesquisa de $\operatorname{IgG}$ e de $81,5 \%$ para a pesquisa de $\operatorname{Ig} M$. Estimando-se o índice de concordância ajustada (K) encontrou-se, $\mathrm{K}=70,8 \%$ e $\mathrm{K}=1,3 \%$ para $\lg \mathrm{G}$ e IgM, respectivamente. Considerando-se o critério de concordância, $74 \%>K>41 \%$, os testes foram avaliados como de nível regular de concordância, para pesquisa de IgG e de nível pobre de concordância para pesquisa de lgM.

$\mathrm{Na}$ Tabela 3, pode-se observar os resultados dos 28 pacientes do grupo A pelas técnicas de ELISA e IFI para pesquisa de lgG. 
Tabela 3 - Resultados da sorologia de 28 pacientes, com clínica sugestiva de toxoplasmose aguda, obtidos através das técnicas de ELISA e IFI para pesquisa de anticorpos da classe IgG. Grupo A.

\begin{tabular}{lccccccc}
\hline Métodos & $\begin{array}{c}\text { Soros não } \\
\text { reagentes }\end{array}$ & Soros & \multicolumn{5}{c}{ Títulos dos soros reagentes } \\
\cline { 2 - 7 } & $4 / 28$ & $24 / 28$ & $1: 16$ & $1: 64$ & $1: 256$ & $1: 1024$ & $1: 4096$ \\
\hline IFI & 14,2 & 85,7 & $1 / 24$ & $5 / 24$ & $4 / 24$ & $8 / 24$ & $4 / 24$ \\
$\%$ & $2 / 28$ & $26 / 28$ & $1 / 26$ & 20,8 & 16,7 & 33,3 & 16,7 \\
ELISA & 7,1 & 92,8 & $2 / 26$ & $4 / 26$ & $9 / 26$ & $10 / 26$ \\
$\%$ & & 3,8 & 7,6 & 15,3 & 34,6 & 38,4 \\
\hline
\end{tabular}

A pesquisa de $\lg \mathrm{M}$ revelou $22(78,5 \%)$ soros não reagentes e $6(21,4 \%)$ reagentes dos quais apenas $1(16,6 \%)$ apresentou sorologia reagente a 1:16, $2(33,4 \%)$ até $1: 64$ e $3(50 \%)$ até $1: 256$. Pela técnica de ELISA 23 (82,1\%)soros foram negativos enquanto $5(17,8 \%)$ foram positivos. Destes $4(80 \%)$ reagiram até $1: 16$, enquanto apenas $1(20 \%)$ reagiu até $1: 64$.

Com relação ao grupo $B$, os resultados da pesquisa de lgG estão apresentados na Tabela 4.

Tabela 4 - Resultados da sorologia de 30 pacientes, gestantes, obtidos através das técnicas de ELISA e IFI para pesquisa de anticorpos das classes IgG. Grupo B.

\begin{tabular}{lccccccc}
\hline Métodos & Soros não & Soros & \multicolumn{5}{c}{ Títulos dos soros reagentes } \\
\cline { 3 - 7 } & reagentes & reagentes & $1: 16$ & $1: 64$ & $1: 256$ & $1: 1024$ & $1: 4096$ \\
\hline IFI & $13 / 30$ & $17 / 30$ & $6 / 17$ & $7 / 17$ & $3 / 17$ & $1 / 17$ & $0 / 17$ \\
$\%$ & 43,3 & 56,6 & 35,2 & 41,1 & 17,6 & 5,8 & 0 \\
ELISA & $7 / 30$ & $23 / 30$ & $5 / 23$ & $7 / 23$ & $6 / 23$ & $3 / 23$ & $2 / 23$ \\
$\%$ & 23,3 & 76,6 & 21,7 & 30,4 & 26,0 & 13,0 & 8,6 \\
\hline
\end{tabular}

Todas as pacientes do grupo B foram nãoreagentes pela técnica de IFI-IgM; enquanto pela ELISA $28(93,3 \%)$ das pacientes foram não reagentes e $2(6,6 \%)$ foram reagentes com títulos iguais a $1: 16$.
Os resultados do grupo $\mathrm{C}$, quanto a presença de anticorpos das classes lgG estão apresentados na Tabela 5.

$\mathrm{Na}$ IFI-IgM todos os soros foram nãoreagentes, sendo que pela técnica de ELISA 21

Tabela 5 - Resultados da sorologia de 28 pacientes, com infecção por HIV e sorologia para toxoplasmose, obtidos através das técnicas de ELISA e IFI para pesquisa de anticorpos da classe lgG. Grupo C.

\begin{tabular}{|c|c|c|c|c|c|c|c|}
\hline \multirow[t]{2}{*}{ Métodos } & \multirow{2}{*}{$\begin{array}{l}\text { Soros não } \\
\text { reagentes }\end{array}$} & \multirow{2}{*}{$\begin{array}{c}\text { Soros } \\
\text { reagentes }\end{array}$} & \multicolumn{5}{|c|}{ Títulos dos soros reagentes } \\
\hline & & & $1: 16$ & $1: 64$ & $1: 256$ & $1: 1024$ & $1: 4096$ \\
\hline$\overline{I F I}$ & $3 / 28$ & $25 / 28$ & $3 / 25$ & $9 / 25$ & $4 / 25$ & $9 / 25$ & $0 / 25$ \\
\hline$\%$ & 10,7 & 89,2 & 12 & 36 & 16 & 36 & 0 \\
\hline ELISA & $2 / 28$ & $26 / 28$ & $6 / 26$ & $4 / 25$ & $2 / 25$ & $9 / 25$ & $5 / 25$ \\
\hline$\%$ & 7,1 & 92,8 & 23 & 15,3 & 7,6 & 34,6 & 19,2 \\
\hline
\end{tabular}

(75\%) soros foram não-reagentes e 7 (25\%) foram reagentes, dos quais $4(57,1 \%)$ reagiram até $1: 16$ e $3(42 \%)$ até $1: 64$.

$\mathrm{Na}$ análise dos pacientes do grupo $\mathrm{D}$ foram obtidos $11(64,7 \%)$ pacientes não-reagentes pela IFI-IgG e apenas $6(35,2 \%)$ reagentes, dentre estes $4(66,6 \%)$ indivíduos apresentaram soros com títulos até 1:16 e $2(33,3 \%)$ com títulos de 1:256. Pela técnica de ELISA-IgG foi obtido o mesmo resultado, sendo que $1(16,6 \%)$ soro reagiu até $1: 16,1(16,6 \%)$ até $1: 64,3(50 \%)$ até $1: 256$ e $1(16,6 \%)$ até $1: 1024$. A pesquisa de anticorpos da classe IgM pela IFI não apresentou nenhum resultado positivo, enquanto que pela ELISA apenas 1 (5,8\%) soro foi positivo com título de 1:16, apresentando leitura próximo ao cutoff.

A análise da correlação entre as técnicas de ELISA-IgG e IFI-lgG através dos títulos obtidos 
foi de $r=0,556$, indicando uma correlação positiva moderada entre as técnicas, embora na análise da correlação entre os soros do grupo " $C$ " tenha apresentado um $r=0,387$, indicando uma correlação positiva moderada porém mais fraca do que os outros dois grupos $(r=0,633$ para 0 grupo "B" e $r=0,577$ para o grupo $A$ ).

A correlação entre as técnicas IFI e ELISA para pesquisa de $\operatorname{lgM}$, apresentou $r=-0,023$, sendo considerada uma correlação negativa fraca.
Os resultados da correlação títulolY dos soros analisados para pesquisa de $\lg \mathrm{G}$ foi de $r=0.552$, sendo considerada positiva moderada, não apresentando variação considerável quando analisados em relação aos soros do mesmo grupo $(r=0,576$ para o grupo $A, r=0,541$ para o grupo $B$ e $r=0,374$ para o grupo $C$ ).

Em relação a ELISA-IgM, a correlação entre o título e a unidade arbitrária foi de $r=0,562$, sendo considerada uma correlação positiva moderada.

\section{DISCUSSÃO}

Na padronização de técnicas o painel de indivíduos positivos e negativos deve ser escolhido cuidadosamente. Sabe-se que o caráter principal para a escolha do grupo positivo para determinada infecção é o isolamento ou detecção do agente em questão, indicando um processo agudo. Com relação a toxoplasmose, o encontro do parasita torna-se muito difícil, uma vez que a maioria da população já teve contato com o agente apresentando quadros subclínicos e/ou memória sorológica, sendo a clínica apenas sugestiva ${ }^{1326}$.

No presente estudo, a partir dos 103 soros utilizados a prevalência da infecção foi de $78,6 \%$, o que. concorda com os dados de Nogueira et $\mathrm{al}^{23}$ que relata que $70 \%$ da população no Brasil apresenta anticorpos anti- $T$. gondii, bem como com o trabalho de Coutinho et al ${ }^{11}$ que encontrou uma prevalência de $78,7 \%$ num estudo com 6079 indivíduos do Rio de Janeiro, em um período de sete anos.

Analisando a correlação $(r)$ entre os dois métodos para pesquisa de lgG nos 86 soros dos três grupos estudados ( $A, B$ e $C$ ), obtivemos uma correlação positiva $(r=0,556)$, concordando com 0 trabalho de Van Knapen ${ }^{33}$. Este autor sugere que o teste de ELISA pode ter boa aplicabilidade no diagnóstico da toxoplasmose em testes de triagem sorológica (identificação de soros positivos e negativos), o que também foi evidenciado em nosso estudo a partir da análise dos valores de copositividade e conegatividade entre as técnicas de IFI e ELISA.

A diferença entre os resultados obtidos pela técnica de ELISA e IFI pode estar relacionada aos diferentes antígenos utilizados, uma vez que na técnica de IFI utilizou-se parasitas íntegros (antígenos de membrana que estimulam a produção de anticorpos mais precocemente na infecção), enquanto que no ELISA utilizou-se antígenos solúveis (citoplasmáticos), cujos anticorpos seriam formados mais tardiamente na infecção ${ }^{33}$. Além disso, o fato de soros nãoreagentes pela técnica de ELISA serem reagentes por outros métodos sorológicos clássicos, segundo Van Knapen ${ }^{33}$ pode estar relacionado a maior especificidade, menor sensibilidade, diferentes antígenos e a qualidade do conjugado utilizado no teste ${ }^{33}$.

Camargo et $\mathrm{al}^{7}$ utilizando a técnica de ELISA para IgG e IgM anti-T. gondii encontraram boa correlação da ELISA-IgG com o teste de IFI-IgG, enquanto que no presente trabalho esta correlação foi moderada. No entanto, os nossos resultados estão de acordo com os de Camargo et $\mathrm{al}^{7}$ no que se refere a ELISA-IgM mostrar-se mais sensível do que a IFI-IgM. Nos estudos de Van Knapen ${ }^{33}$, o uso do OPD na revelação das placas gerou densidades ópticas maiores, embora a discriminação entre amostras com maior e menor positividade se tornasse de difícil observação principalmente por leitura visual.

$\mathrm{Na}$ realização da técnica de ELISA-IgG qualitativa é necessário considerar as diferenças entre placas e dentro destas devido a diferenças durante os passos de incubação que geram variações na faixa de $10 \%$, o que é importante na obtenção de resultados ${ }^{12}$. Devido a este motivo, na padronização do antígeno e no estabelecimento do cutoff, os soros controles foram processados em diluições e repetidos em quatro placas distintas, a fim de que fossem minimizadas estas diferenças. O estabelecimento do cutoff a partir dos soros negativos diluídos a 1:16, deu-se devido a variações mínimas entre os cutoff obtidos nestes mesmos soros em diluições maiores $(1: 64,1: 256,1: 1024$ e 1:4096).

A detecção de IgM específica para a toxoplasmose é muito importante no seu diagnóstico e deve ser realizada e lida com muito 
cuidado. Resultados falso positivos podem surgir devido a especificidade do conjugado e presença de fator reumatóide ou antinuclear no soro de pacientes; enquanto que resultados falso negativos podem ser gerados por altas concentrações de IgG no soro. Van Knapen ${ }^{33}$ também verificou que pela ELISA foi possível encontrar mais amostras positivas do que com IFI, sugerindo que o ELISA-IgM demonstra anticorpos da classe lgM produzidos não apenas na fase inicial da infecção, bem como para outros antígenos. Apesar destas considerações, no presente experimento, os resultados positivos pela técnica de ELISA-IgM talvez não sejam indicadores de pacientes em fase aguda (falso positivos), uma vez que a IFI (técnica de referência por várias instituições) apresentou resultados negativos e as leituras dos soros pela técnica de ELISA-IgM foram muito próximas ao valor de cutoff da placa sendo que a maioria destes pacientes não apresentavam clínica sugestiva para toxoplasmose nem confirmação parasitológica. Além disso, analisando a Tabela 2 , pode-se verificar que este teste sorológico apresentou um índice de concordância ajustado (K) muito baixo, o que indica pouca confiabilidade da técnica em relação a IFI.

No ELISA-IgM, embora sejam observadas diferenças quanto ao tipo de antígeno utilizado, como já foi proposto em relação a ELISA-IgG, o uso do antígeno solúvel apresentou melhores resultados. Assim como no presente estudo (Tabela 2), Van Knapen ${ }^{33}$ encontrou apenas boa conegatividade na avaliação do ELISA-IgM nos soros devido ao número insuficiente de soros IgM-reagentes para toxoplasmose, sendo que a técnica de IFI-IgM nunca alcançou uma copositividade com o ELISA-IgM de mais de $60 \%$. Este fato também foi observado em nosso estudo, onde a copositividade foi de $6,66 \%$ (ELISA/IFI) e de 16,66\% (IFI/ELISA). Camargo, Camargo et al ${ }^{8}$ e Porstmann e Kiessig ${ }^{25}$ sugerem que para uma maior especificidade da técnica de ELISA para pesquisa da classe lgM, deve-se proceder a captura dessas imunoglobulinas com anticorpos monoclonais e posterior revelação com antígenos marcados (como por exemplo pela técnica de ISAGA ${ }^{316}$ ). Mineo et $a^{21}$ propõem o uso da técnica de ELISA reversa para a pesquisa de $\operatorname{lgM}$, a qual, neste trabalho, não apresentou reatividade cruzada com soros de pacientes com outras patologias nem com amostras contendo fator reumatóide lgM.

Johnson et $\mathrm{al}^{17}$ avaliaram cinco métodos de ELISA para o diagnóstico de toxoplasmose aguda, utilizando dois testes de ELISA com antígenos recombinantes, os quais apresentaram E e VPP de $100 \%$ e VPN de $87,8 \%$ e $S$ de $81,3 \%$; e três técnicas comerciais com antígeno derivado de parasita íntegro. As técnicas comerciais mostraram VPP na faixa de $81,6-100 \%$ e VPN de $87,8-100 \%$ com $S$ de $81,3 \%-100 \%$ e $E$ de $83,7-100 \%$. A técnica de ELISA com antígeno produzido e padronizado neste trabalho apresentou sensibilidade (96,77\%) semelhante as técnicas comerciais avaliadas por Jonhson et al ${ }^{17}$, embora a especificidade (75\%) de nosso teste tenha sido menor, enquanto que tanto o VPP $(83,33 \%)$ quanto o VPN $(94,74 \%)$ apresentaramse dentro da faixa apresentada por estes autores.

Segundo Wainstein et $\mathrm{al}^{34} \mathrm{o}$ significado da IFI para toxoplasmose (no soro) no diagnóstico da encefalite toxoplásmica permanece alvo de controvérsia, porém o baixo número de soros positivos para detecção de $\operatorname{lgM}$ confirma a suposição de que a encefalite toxoplásmica seja uma reativação da forma latente. No presente estudo, nenhum dos 28 pacientes infectados pelo vírus HIV foram soro-reagentes pela IFI-IgM concordando com os achados de Wainstein et $\mathrm{a}^{34}$, onde entre 516 soros avaliados, apenas três foram positivos. Estes mesmo autores relatam que os títulos encontrados em relação a IFI-IgG não apresentam valor diagnóstico, mas devido a alta sensibilidade da técnica (IFI), que foi de $95 \%$, a ausência de anticorpos específicos é interpretada como informação importante para a exclusão da possibilidade de encefalite toxoplásmica, embora a ausência de títulos elevados não afaste a possibilidade da encefalite. A acurácia diagnóstica foi aumentada através de testes seriados permitindo a seleção de pacientes com títulos altos (títulos acima de 1:1000) e da associação dos resultados sorológicos com resultados da tomografia computadorizada gerando uma sensibilidade de $83 \%$ e o aumento da especificidade para $56 \%$, enquanto que anteriormente esta especificidade era de $30 \%$. Já em nossos estudos a sensibilidade $(83,87 \%)$ e especificidade $(79,16 \%)$ da técnica de IFI foram superiores aos estudos de Wainstein et $\mathrm{al}^{34}$.

Nas Tabelas 2, 3 e 4, estão demonstrados a análise dos soros dos pacientes através das técnicas de ELISA-IgG e IFI-IgG permitindo que pudéssemos conhecer sorologicamente os pacientes estudados. Afrequência de títulos altos (títulos iguais ou superiores a 1:1024) foi maior no grupo A (pacientes com clínica sugestiva de toxoplasmose) do que no grupo B (gestantes) 
que foi de $5,88 \%$. No grupo de pacientes infectados pelo vírus HIV (grupo C), uma vez que a encefalite toxoplásmica consiste geralmente de um processo de reativação, $82,29 \%$ foram sororeagentes, sendo que $36 \%$ apresentavam sorologia alta, embora a presença de títulos sorológicos não seja diagnóstico para a encefalite toxoplásmica, devendo ser associado a outros métodos de diagnóstico ${ }^{34}$. Aassociação de títulos altos (iguais ou maiores que 1024) com a detecção do parasita não apresentou diferenças significantes neste trabalho, em nenhum dos grupos estudados.
A partir destes resultados podemos concluir que o teste de ELISA-IgG, padronizado neste trabalho, mostrou-se eficiente para a triagem sorológica de pacientes no diagnóstico da toxoplasmose, apresentando correlação positiva moderada com o teste de IFI-IgG. Já o teste de ELISA-IgM avaliado neste trabalho mostrou-se pouco eficiente para a emissão de resultados positivos na toxoplasmose, e com boa eficiência para emissão de resultados negativos, embora sua concordância baixa com o teste de IFI, sugira pouca confiabilidade nos resultados obtidos como um todo.

\section{AGRADECIMENTOS}

Ao Dr. Mauro C. A Marzochi da ENSP FIOCRUZ pela revisão do trabalho; às Dras. Elizabete Neves e Maria Clara G. A Galhardo do
Hospital Evandro Chagas - FIOCRUZ e ao Dr. Nilo Vidigal do Instituto Fernandes Figueira - FIOCRUZ pela triagem dos pacientes e colheita do material.

\section{REFERÊNCIAS BIBLIOGRÁFICAS}

1. Amato Neto V, Campos R, Barazzi RG, Duarte MIS. Toxoplasmose. Editora Savier, São Paulo 1982.

2. Angel SO, Matrajt M, Margarit J, Nigro M, Illescas E, Pszenny V, Amendoeira MRR, Guarnera E, Garberi JC. Screening for active toxoplasmosis in patients by DNA hybridization with the ABGTg7 probe in blood samples. Journal of Clinical Microbiology 35:591-595, 1997.

3. Ashburn D, Joss AWL, Pennington TH, Ho-Yen DO. Specificity and usefulness of an IgE immunosorbent agglutination assay for toxoplasmosis. Journal of Clinical Pathology 48:64-69, 1995.

4. Berquó ES, Souza JMP, Gotlieb SLD. Bioestatística. 1a edição rev, Editora Paulista Universitária, São Paulo, 1981.

5. Burg JL, Grover CM, Pouletty P, Boothroyd JC. Direct and sensitive detection of a pathogenic protozoan, Toxoplasma gondii, by polymerase chain reaction. Journal of Clinical Microbiology 27:1787-1792, 1989.

6. Camargo ME, Ferreira AW, Mineo JR, Takiguti CK, Nakahara OS. Immunoglobulin $G$ and immunoglobulin $M$ enzyme-linked immunosorbent assay and defined toxoplasmosis serological patterns. Infection and Immunity 21:55-58, 1978.

7. Camargo ME, Ferreira AW, Rocca A, Belem ZR. Um teste prático para a sorologia da toxoplasmose: o teste de hemaglutinação. Estudo comparativo com os testes de imunofluorescência e imunoenzimático de captura de IgM. Revista Brasileira de Patologia Clinica 22:196-201, 1986.

8. Camargo ME, Leser PG, Leser WSP. Diagnostic information from serological tests in human toxoplasmosis. A comparative study of hemagglutination, complement fixation, $\lg \mathrm{G}$ and $\lg \mathrm{M}$-immunofluorescence tests in 3752 serum samples. Revista do Instituto de Medicina tropical de São Paulo 18:215-226, 1976.
9. Camargo ME. Alguns aspectos atuais do diagnóstico laboratorial da toxoplasmose. Anais da Academia Nacional Medicina, 155:236-239, 1995.

10. Coutinho SG, Andrade CM, Malvar GS, Ferreira LF. Análise comparativa entre as sensibilidades da reação indireta de anticorpos fluorescentes e da reação de Sabin-Feldman na pesquisa de anticorpos séricos para toxoplasmose. Revista da Sociedade Brasileira de Medicina Tropical 4:315-325, 1970.

11. Coutinho SG, Souza WJS, Camillo-Coura L, Marzochi MCA, Amendoeira MRR. Levantamento dos resultados das reações de imunofluorescência indireta para toxoplasmose em 6079 pacientes de ambulatório ou gestantes no Rio de Janeiro realizadas durante o exame de 1970-1977. Revista do Instituto de Medicina Tropical de São Paulo 23:48-56, 1981.

12. Denmark JR, Chessum BS. Standardization of enzymelinked immunosorbent assay (ELISA) and detection of Toxoplasma antibody. Medical Laboratory Science 35:227-232, 1978.

13. Derouin F, Mazeron MC, Garin YJF. Comparative study of tissue culture and mouse inoculation methods for demonstration of Toxoplasma gondii. Journal of Clinical Microbiology 25:1597-1600, 1987.

14. Guimarães MC, Coutinho SG, Antunes CMF. Normas para a sorologia de moléstias parasitárias. Revista da Sociedade Brasileira de Medicina Tropical 20:55-58, 1987.

15. Hajeer AH, Balfour AH, Mostratos A, Crosse B. Toxoplasma gondii: detection of antibodies in human saliva and serum. Parasite Immunology 16:43-50, 1994.

16. Jacobs J, Lunde MN. A hemaglutination test for toxoplasmosis. Journal of Parasitology 43:308-314, 1957. 
17. Johnson AM, Roberts $H$, Tenter AM. Evaluation of a recombinant antigen ELISA for diagnosis of acute toxoplasmosis and comparison with traditional antigen ELISAs. Journal of Medical Microbiology 37:404-409, 1992

18. Laurentino-Silva V. Leishmanioses caninas: padronização e avaliação de métodos imunoenzimáticos para pesquisa de IgG sérica. Tese de Mestrado. Universidade Federal Rural do Rio de Janeiro, Rio de Janeiro, 1996.

19. Levin J. Estatística Aplicada a Ciências Humanas. 2a edição, Harbra, São Paulo, 1987.

20. Lowry OH, Rosebrough NJ, FarrAL, Randall RJ. Protein measurement with the folin phenol reagent. Journal of Biological Chemistry 193:265-275, 1951.

21. Mineo JR, Camargo ME, Ferreira AW, Almeida G. Pesquisa de anticorpos IgM anti-Toxoplasma gondii por meio de técnica imunoenzimática reversa. Revista do Instituto de Medicina Tropical de São Paulo 28:6-11, 1986.

22. Nicolle $\mathrm{C}$, Manceaux L. Sur une infection à corps de Leishman (ou organimes voisins) du gondi. Clinical Reviews of Academic Science 147:763-766, 1908.

23. Nogueira AS, Moreira RB, Pereira NG. Toxoplasmose Diagnóstico e tratamento. Jornal Brasileiro de Medicina 71:38-44, 1996.

24. Patel B, Young Y, Duffy K, Tanner RP, Johnson J, Holliman RE. Immunoglobulin-A detection and investigation of clinical toxoplasmosis. Journal of Medical Microbiology 38:286-292, 1993.

25. Porstmann T, Kiessig ST. Enzyme immunoassay techniques. An overview. Journal of Immunological Methods 150:5-21, 1992.
26. Rey L. Parasitologia: parasitos e doenças parasitárias do homem das Américas e da África. 2a edição. Guanabara Koogan, Rio de Janeiro, 1991.

27. Sabin AB, Feldman HA. Dyes as microchemical indicators of a new immunity phenomenon affecting a protozoon parasite (Toxoplasma). Science 108:660-663, 1948.

28. Sánchez RM, Castillo FC, Grana JP. Comparación de ELISA con las técnicas de inmunofluorescencia indirecta y fijación del complemento para el diagnóstico de la toxoplasmosis. Revista Cubana Medicina Tropical 37:269-277, 1985.

29. Sounis E. Bioestatística, $2^{a}$ Edição rev, McGraw-Hill do Brasil, Ltda,1979.

30. Souza WJS, Volpini ICS, Henrique MF, Coutinho SG. Imunofluorescencia (IF) para toxoplasmose em frações IgM de soro humano. Revista Brasileira de Patologia Clinica 29:47-50, 1993.

31. Stepick-Biek P, Thulliez P, Araujo FG, Remington JS. IgA antibodies for diagnosis of acute congenital and acquired toxoplasmosis. Journal of Infectious Diseases 162:270$273,1990$.

32. Toman K. Sensibilidad, especificidad y valor predictivo de los tests diagnosticos. Boletin de la Union International contra la Tuberculosis 56:19-30, 1981.

33. Van Knapen FV. Immunodiagnosis of Toxoplasmosis. Drukkerij Veenman BV, Wagenigen, 1984.

34. Wainstein MV, Wolffenbuttel L, Lopes DK, Gonzales HE, Golbspan L, Ferreira L, Sprinz E, Kronfeld M, Edelweiss MI. Sensibilidade e especificidade do diagnóstico clínico, sorológico e tomográfico da encefalite por Toxoplasma gondii na síndrome da imunodeficiência adquirida (SIDA). Revista da Sociedade Brasileira de Medicina Tropical 26:71-75, 1993. 